\title{
Study on Urban Construction Land Suitability Evaluation in China's Southwestern Frontier Mountainous Area: A Case Study in Longchuan County, Yunnan Province
}

\author{
HE Yi-mei, YANG Zi-sheng ${ }^{*}$, ZHANG Bo-sheng, Xu Ming-jun \\ Institute of Land \& Resources and Sustainable Development, Yunnan University of Finance and \\ Economics, Kunming 650221, China
}

heyimei6666@126.com ,yangzisheng@126.com, zbs1768@126.com, xumingjun0711@163.com

KEYWORD:Mountainous area; Constructive land; Suitability evaluation; Comprehensive suitability index; China's southwestern frontier area

ABSTRACT: Carrying out the evaluation of land suitability for urban construction in mountainous areas will provide a fundamental basis for building mountainous cities. This study carried out a full evaluation on suitability for urban construction and its suitability grade of each evaluation unit in the mountainous areas of Longchuan County, which is a mountainous border county located in southwest China, based on the latest 1:10000 land-use map produced from the County's Second National Land Survey, against the 12 evaluation indicators, using an approach combining the "Extreme Conditions Method" and "Suitability Index Method", and with the help of GIS technology. The results show that, the area of mountainous land suitable for construction and no-suitable for construction respectively account $13.01 \%$ and $86.99 \%$. And first-class, second and third-class of land suitable for construction should be composited the ratio of about 12:43:45. The suitability evaluation index system and method developed in this paper is applicable for evaluating the construction land suitability in mountainous areas of Yunnan Province, and will provide theoretical and technical support for land policy measures which strengthen the protection of farmland and promote the scientific development of urbanization in Yunnan Province and even similar mountainous areas of the whole China.

\section{Introduction}

Yunnan, as a typical mountainous border province in southwestern China, has nearly $94 \%$ of its territory being mountainous areas and only as low as $6 \%$ being flatlands. Flatland, as referred to herein, means any inter-mountain basin, valley or a flat land having a slope less than or equal to $8^{\circ}$ over a contiguous stretch that is either longer than or equal to 1 square kilometers. Accordingly, the concept of mountainous areas, as referred to throughout the paper, means any area, other than flatland, having a slope greater than $8^{\circ}$, within a given territory. For a long time up to the date, Flatland is not only where agricultural production and practice, but also urbanization and industrialization, mainly take place in Yunnan. Presently, nearly $30 \%$ of the Province's flatland have been occupied by construction projects of various types and natures, and Yunnan Province is seeing a rapid decline in its high-quality arable land available province-wide. If leave it as it is going now without making a change to the traditional way of urban development, all the flat lands currently available province-wide will be completely used up and disappear in just several, even in one or two, decades, and consequently, the Province will lose its crucial base for regional food security and sustainable development. The situation is critical and serious, indeed. The Government of Yunnan Province therefore devised and implemented, in the first half of 2011, the strategy of "Protecting Flatlands and Farmlands and Constructing Mountainous Cities", which is hereinafter referred to as "Cities-on-Mountains Strategy". One of the preconditions, also a crucial base and support, for the successful implementation of the strategy is having a full evaluation of the suitability of mountainous lands for urban construction. From an overall view, such suitability evaluation still remains a weak link without well-established and proven theory, methodology, evaluation indicators, 
standard and techniques. In the light of this, and with due consideration of the said "Cities-on-Mountains Strategy", this research conducted a proper evaluation of the suitability of mountainous lands for urban development within the territory of Longchuan County, a mountainous county located in the southwestern Yunnan Province, and determined land resources distribution for urban construction in order to explore feasibility of urban construction extending to mountainous areas, developing mountainous towns, and resolving the feasibility of cultivated land protection, as well as advancing the protection of highly-qualified farmlands in flatland areas in Yunnan Province or even similar mountainous areas of the whole nation and promoting land policies for scientific urbanization development.

\section{Overview of the study area}

Longchuan County is a border county located southwest of Dehong Dai and Jingpo Autonomous Prefecture, Yunnan Province, southwest China, at a longitude between 97 $39^{\prime}$ and $98^{\circ} 17^{\prime}$ and a latitude between $24^{\circ} 08^{\prime}$ and $24^{\circ} 39^{\prime}$. It borders Myanmar west over a $50.9 \mathrm{~km}$-long border line. The County's total land area is 1,872.91 square kilometers, out of which $16.73 \%$ are flatlands and the rest, i.e. $83.27 \%$, are mountainous areas, including highlands.

The County lies south of the west slope of the Gaoligong Mountain. Topographically, it is a low-to-medium altitude mountainous area with basins and wide valleys in southwest Yunnan. The highest elevation within the territory of the county is $2,618.8 \mathrm{~m}$, and the lowest is $780 \mathrm{~m}$, with a difference of up to $1,838.8 \mathrm{~m}$ between the highest and the lowest elevations. The county has a South Asian tropical monsoon climate, featuring abundant rainfall and heat, sufficient sunshine, and a wide climatic diversity. The county's historical average annual temperature is $18.9^{\circ} \mathrm{C}$ and precipitation is $1,595 \mathrm{~mm}$. The county is frequently struck by natural disasters, mainly drought, flood, soil erosion, mud-rock slide, etc., though the natural conditions are overall favorable throughout the county.

\section{Research methods}

\section{Contents of the evaluation}

The fundamental contents of suitability evaluation for mountainous urban construction can be determined as per the strategy of "protecting farmland in flatland areas and constructing mountainous cities".

Evaluation on suitability of urban construction in mountainous areas According to characters of southwest mountainous areas in China, urban construction suitability can be classified into suitability and unsuitability. Hence, within the scope of mountainous area in this county, each land parcel was assessed as suitable or unsuitable through the evaluation.

Grading of mountainous land suitability for urban construction

Within the scope of lands suitable for construction, the degree of suitability can be further classified into three levels, namely, highly suitable, moderately suitable and lowly suitable, respectively corresponds to grades 1, 2 and 3 suitable lands with mountainous construction land suitability (HE et al., 2014).

\section{Principles of the evaluation}

The research involved four principles, with references of A Framework for Land Evaluation (FAO, 1976), 1:1000000 Land Resource Map of China (ECLRMC, 1990), and the strategy of "protecting farmland in flatland areas and constructing mountainous cities" in Yunnan, including:

(1) Suitability and suitable degree of lands for urban construction;

(2)Adjusting measures to local conditions;

(3) Integration of comprehensive analysis and dominant factors;

(4) Sustainability of land use.

\section{Building of evaluation index system}

The evaluation index system of mountainous land for construction should embody the 
characteristics of mountain towns themselves, and consider the availability of data and measurability of index. Therefore, the index system of land suitability in mountainous areas was constructed under the principles of suitability evaluation of mountainous urban construction land.

Evaluation index

The research concerned 12 evaluation indices, namely, (1)slope, (2)lithology, soil texture, hydrologic condition, and subgrade bearing capacity, (3)geological disaster and the threats, (4) distribution distance of fault zones, (5)ground work and construction cost, (6) constructed over mineral, (7) water supply and drainage, (8)afforestation habitat, (9) transportation, (10) distribution of basic farmland protection, (11)eco-environment security, and (12) natural and cultural heritage protection.

Index grading

Every indice can be classified into 4 grades, corresponding to highly suitable, moderately suitable, lowly suitable and unsuitable grades. For example, the index of slope can be divided into slopes $<$ $6^{\circ}, 6^{\circ}-15^{\circ}, 15^{\circ}-25^{\circ}$ and $>25^{\circ}$.

\section{Evaluation unit}

Generally, an evaluation unit is a basic pattern spot of 1:10 000 land-use map in the Second National Land Survey. However, if the area of a spot is so large as to span several slope levels, such spot will be divided into several individual evaluation units.

\section{Technical methods of evaluation}

The evaluation on land suitability is actually a process making comparisons on land use types and land properties (12 evaluation factors above) representing land quality of every evaluation unit, concerning interplay and coordination, namely matching.

With Arcgis 9.3, land quality property and purpose were compared for evaluated units, and suitability of every unit was analyzed as per "extreme conditions method" and "suitability index method", with corresponding grade (highly suitable, moderately suitable, lowly suitable and unsuitable) proposed.

\section{Concrete steps of the evaluation}

Determination of suitability or unsuitability of evaluation units for urban construction as per "extreme conditions method"

With 7 factors above considered, it is ruled that the lands with slope $\geq 25^{\circ}$, high-risk zones with geological disaster, the zones with fault zone at $500 \mathrm{~m}$, important constructed over mineral zones, basic farmland conservation areas, eco-environment safety control zones, and natural and cultural heritage reserves all belong to lands unsuitable for construction. Otherwise, the lands are suitable for construction.

Determination of suitability grade (highly suitable, moderately suitable, and lowly suitable) as per "extreme conditions method" and "suitability index method"

At first, grade 1 land is determined as per "extreme conditions method". Generally speaking, the lands with slope $\leq 8^{\circ}$ in suitable areas are collectively named grade 1 suitable lands in Yunnan, and then grades 2 and 3 suitable lands can be determined by using "suitability index method" (HE et al., 2014).

\section{Determination of single evaluation factor index}

Theoretically, single evaluation factor index is in the range of 0-100. Considering accurate quantification of every evaluation unit is hardly to be achieved, assignment could proceed as per high, moderate and low suitability of deferent evaluation factors (to see Table 1).

Table 1 Assignments of single factor index of urban construction land suitability in mountainous areas

\begin{tabular}{cccc}
\hline Suitability grade & Highly suitable & Moderately suitable & Lowly suitable \\
\hline Value range & $100-80$ & $80-60$ & $60-40$ \\
Specific value & 85 & 65 & 45 \\
\hline
\end{tabular}

Determination of comprehensive suitability index (CSI)

(1) Calculations

In order to make a comprehensive evaluation on suitability grade of mountainous areas for urban construction, quantitative index of comprehensive evaluation was proposed, namely, CSI, to reflect 
suitability degree of construction lands in mountainous areas in a quantitative way.

$C S I=w_{1} \cdot I_{1}+w_{2} \cdot I_{2}+w_{3} \cdot I_{3}+w_{4} \cdot I_{4}+w_{5} \cdot I_{5}+w_{6} \cdot I_{6}$

$+w_{7} \cdot I_{7}+w_{8} \cdot I_{8}+w_{9} \cdot I_{9}+w_{10} \cdot I_{10}$

, where $\mathrm{I}_{1}, \mathrm{I}_{2}, \mathrm{I}_{3}, \mathrm{I}_{4}, \mathrm{I}_{5}, \mathrm{I}_{6}, \mathrm{I}_{7}, \mathrm{I}_{8}, \mathrm{I}_{9}$ and $\mathrm{I}_{10}$ represent evaluation factors' indices of suitability grades, corresponding to slope, lithology, soil texture, hydrologic condition, and subgrade bearing capacity, geological disaster and the threats, distribution distance of fault zones, ground work and construction cost, constructed over mineral, water supply and drainage, afforestation habitat, transportation, distribution of basic farmland reserve, eco-environment security and natural and cultural heritage protection. Furthermore, $\mathrm{w}_{1}, \mathrm{w}_{2}, \mathrm{w}_{3}, \mathrm{w}_{4}, \mathrm{w}_{5}, \mathrm{w}_{6}, \mathrm{w}_{7}, \mathrm{w}_{8}, \mathrm{w}_{9}$ and $\mathrm{w}_{10}$ are weights of $\mathrm{I}_{1}, \mathrm{I}_{2}, \mathrm{I}_{3}, \mathrm{I}_{4}, \mathrm{I}_{5}, \mathrm{I}_{6}, \mathrm{I}_{7}, \mathrm{I}_{8}, \mathrm{I}_{9}$ and $\mathrm{I}_{10}$. It is notable that totaling 12 indices were included in the research, of which basic farmland protection and natural and cultural heritage protection are special factors not considered in suitability grade evaluation for construction.

The higher CSI value, the higher suitability degree of construction lands.

(2) Determination methods and results of index weights

In general, effects of evaluation indices tend to be volatile, and therefore, it is necessary to determine weights of different indices, which constitutes a key chain of suitability evaluation for urban construction in mountainous areas. Specifically, the determination method of weights includes principal component analysis, analytic hierarchy process, and Delphi method, of which the last one is much popular. Delphi method organizes experts for assignment or grading on weights and then the factors' weights would be marked for the $2^{\text {nd }}$ and $3^{\text {rd }}$ rounds after estimation of feedback probability, to converge the assignments. Finally, the coordinated factors' weights can be obtained.

As per Delphi method, 15 professionals were organized to grade evaluation factors above, and the weights of different indices can be obtained (to see Table 2).

Table 2 Factors and weights of suitability evaluations for urban construction in mountainous areas

\begin{tabular}{|c|c|}
\hline Evaluation factors & Weights \\
\hline 1 Slope & 0.15 \\
\hline 2 Lithology, soil texture, hydrologic condition, and subgrade bearing capacity & 0.12 \\
\hline 3 Geological disaster and the threats & 0.14 \\
\hline 4 Distribution distance of fault zones & 0.12 \\
\hline 5 Ground work and construction cost & 0.10 \\
\hline 6 Constructed over mineral & 0.08 \\
\hline 7 Water supply and drainage & 0.10 \\
\hline 8 Afforestation habitat & 0.04 \\
\hline 9 Transportation & 0.05 \\
\hline 10 Eco-environment security & 0.10 \\
\hline Total & 1.00 \\
\hline
\end{tabular}

\section{Determination of comprehensive suitability degree grade}

As per the method above, CSI values of different evaluation units were computed with GIS, which provides references for classification and determination of comprehensive suitability grade of every evaluation unit. Through repeated analysis, standards of comprehensive suitability grade can be classified (to see Table 3 ).

Table 3 Classification index of comprehensive suitability degree grade of construction land mountainous areas

\begin{tabular}{|c|c|c|c|}
\hline suitability degree grades & Highly suitable & Moderately suitable & Lowly suitable \\
\hline comprehensive suitability index & $>80$ & $80 \sim 75$ & $<75$ \\
\hline
\end{tabular}

\section{Analysis of the results}

The areas and proportions of construction land suitability grades of mountainous area in this County be concluded based on evaluation of suitability for urban construction in mountainous area of Longchuan County.

The results showed that the area of mountainous land suitable for construction reached 20288.70 $\mathrm{hm}^{2}$, taking up to $13.01 \%$, and unsuitable lands at $135669.11 \mathrm{hm}^{2}$, representing $86.99 \%$. As shown 
in Table 1, the unsuitable lands include the lands with slope over $25^{\circ}$ and serious soil erosion, and the lands with lower lithology, soil texture, hydrologic condition, and subgrade bearing capacity, with geological disasters and high ecological sensitivity.

In the suitable lands, grade 1 suitable land was $2426.80 \mathrm{hm}^{2}$, representing $11.96 \%$; grade 2 suitable land was $8722.99 \mathrm{hm}^{2}$, representing $43.00 \%$; grade 3 suitable land was $9138.91 \mathrm{hm}^{2}$, accounting for 45.04\%. It is obvious that slopelands in Longchuan County are dominated by grades 2 and 3 suitable lands, and the proportion of grade 1, 2 and 3 suitable lands is about 12:43:45.

The results indicated that construction land is not appropriate for slopes over $25^{\circ}$ or the lands with other limiting factors, avoiding construction destruction on eco-environment and water and soil conservation projects are recommended for slopes below $25^{\circ}$, which should be major strategy for Longchuan County's sustainable development.

\section{Conclusions}

Most of mountainous lands in Longchuan County are gentle in slope and therefore suitable for urban development, and it is necessary and feasible to adjust urban and rural construction lands to suitable slopelands in mountainous areas by adjustment of construction land layout and reinforcement of farmland protection in flatland areas.

On the other hand, however, considering that $83.27 \%$ of the County's territory are mountains and that the County itself is ecologically fragile and frequently struck by natural disasters like soil erosion, drought, flood, mud-rock slide, etc., effective ecological measures, especially those aiming at soil and water conservation, must be taken in order to successfully implement the strategy of "constructing mountainous cities".

\section{Acknowledgements}

This article is the result of project (No. 41261018) Supported by the National Natural Sciences Foundation of China. We thank Bureau of Land \& Resources of Longchuan County and Bureau of Dehong Dai and Jingpo Nationality Autonomous Prefecture, Yunnan Province for their friendly helps.

\section{References:}

[1] YANG Zi-sheng, ZHAO Qiao-gui, XIN Ling. Land Resources of Yunnan. Beijing: Science and Technology Press of China, 2014 (in Chinese).

[2] HE Yi-mei, YANG Zi-sheng, ZHANG Bo-sheng, et al. Study on urban construction land suitability evaluation in southwestern mountainous areas of Yunnan Province based on the strategy of "protecting farmland in flatland areas and constructing mountainous cities": A case in Lianghe County [J]. Agricultural Science \& Technology, 2014, 15(10): 1774-1777.

[3] FAO. A Framework for Land Evaluation. FAO Soil Bulletin No. 32, Rome, 1976.

[4] The Editorial Committee of 1:1000000 Land Resource Map of China (ECLRMC). The Compiling Standard of 1:1000000 Land Resource Map of China. Beijing: Science Press, 1990 (in Chinese).

[5] YANG Zi-sheng. Analysis on the special factors for evaluating mountainous urban construction land suitability in Yunnan Province. Research of Soil and Water Conservation, 2015, 22 (4) (in Chinese). 